\title{
The Phenomenological Problem of Perception
}

BOYD MILLAR

\section{University at Buffalo}

A perceptual experience of a given object seems to make the object itself present to the perceiver's mind. As P. F. Strawson says, "mature sensible experience (in general) presents itself as, in Kantian phrase, an immediate consciousness of the existence of things outside us" (1979, 47). This phenomenological directness of perceptual experience is the distinctive feature of perceptual phenomenology - it distinguishes our perceptual experiences from every other kind of experience that we enjoy. For example, when you see a book in front of you or hold it in your hands, the book itself seems to be present to you in a way it never does when you merely consciously think or imagine that the book is in front of you.

The question of how to best capture or explain this distinctive phenomenology of perceptual experience has played a crucial role in the debate between the two presently dominant theories of perception: the relational view or naïve realism (the view that to perceive is to stand in a primitive relation of awareness or acquaintance to the world) and the representational or content view (the view that to perceive is to represent the world to be a certain way). ${ }^{1}$ Specifically, philosophers such as Crane (2006, 139-41), Hellie (2007, 266-69), Fish (2009, 19-23), and Kennedy (2009, 578-80), maintain that we should accept naïve realism because it provides a satisfying account of the phenomenological directness of perceptual experience while the content view cannot. Very roughly, the naïve realist complains that since states like thinking and imagining are representational mental states, the content view's proposal that perceptual experiences are representational mental states

The "relational" vs. "representational view" terminology is from Campbell (2002, chap. 6). "Content view" is due to Brewer $(2004,68)$. "Naïve realism" has been used this way by many philosophers, including Martin (1997), Smith (2002), Fish (2009), and Kennedy (2009). 
or events makes it difficult to see why there should be such a profound phenomenological difference between perceiving and thinking or imagining. Conversely, the naïve realist maintains that her view makes it easy to see why perceptual experiences possess their unique phenomenological directness: unlike thinking and imagining, a perceptual experience is partly constituted by physical objects (the very objects that are perceived) and involves a mental relation, namely acquaintance, that is more basic than representation.

However, there is a problem with the naïve realist's story regarding why perceptual experiences possess their distinctive phenomenology: it can't explain the phenomenological directness of illusions and hallucinations. When I suffer an illusion, a property of some object seems to be immediately present to me even though it is not instantiated by that object-but perceptual acquaintance can't explain the phenomenological directness of such an experience since perceptual acquaintance with a property of some particular object requires that the relevant property is instantiated by that object. And when I suffer a hallucination, some object seems be immediately present to me even though there is no such object - but perceptual acquaintance can't explain the phenomenological directness of such an experience since one can only be perceptually acquainted with objects that exist. Thus, naïve realism would seem to have difficulty handling what we might call the phenomenological problem of perception ("the phenomenological problem" for short): how to develop a theory of perception that explains the phenomenological directness of perceptual experience given that illusory and hallucinatory experiences possesses this phenomenological feature, and assuming that such a theory should provide a unified explanation of why veridical, illusory and hallucinatory experiences possess this phenomenological feature. ${ }^{2}$ (For the sake of simplicity, from this point on I will focus on hallucinations and largely ignore illusions).

Naïve realists can respond to the phenomenological problem by denying that hallucinations possess the phenomenological directness possessed by veridical perceptual experiences, or by denying that a theory of perception should provide a unified explanation of why veridical experiences and hallucinations possess this phenomenological feature. Neither response is particularly attractive at first glance; but if the naïve realist is correct that the most plausible rival theory, the content view, can't provide a satisfying account of the phenomenological direct-

2 I use the "phenomenological problem" label to distinguish this issue from the traditional problem of whether mind-independent physical things are, as most of us assume, the direct objects of perceptual experiences (see, for example, Smith [2002]). However, some philosophers think of these two issues as distinct sources of a single problem: see Crane (2011). 
ness of perceptual experience, then quite plausibly one of these responses would constitute the best solution to the phenomenological problem. On the other hand, the content view does not have the same difficulties accommodating hallucinations since representational mental states like beliefs often represent the world to be some way that it isn't. So, if there were some version of the content view that could provide a satisfying account of the phenomenological directness of perceptual experience, it's natural to think such a view would be able to provide a unified explanation of why both veridical and hallucinatory experiences possess this phenomenological feature.

I maintain, first, that a particular variety of the content view in fact provides a fully satisfying account of the phenomenological directness of perceptual experience, and second, that this view provides a unified account of the phenomenological directness of both veridical and hallucinatory experiences. And since, all else being equal, we should prefer a theory that provides a unified account of the distinctive phenomenology of veridical and hallucinatory perceptual experiences to one that does not, we therefore have a powerful reason to prefer this version of the content view to naïve realism. In other words, I maintain that, contrary to what is often assumed, the phenomenological facts concerning perceptual experience are explained better by the content view than by naïve realism - that a particular version of the content view provides the best solution to the phenomenological problem of perception.

First, in $\S 1$, I provide a more detailed description of naïve realism and the content view. In $\S 2$ I describe what I'm calling the phenomenological directness of perceptual experience, highlighting two distinct but closely connected aspects of that phenomenology, and explain why we should think that hallucinations possess this phenomenological feature. In $\S 3$ I outline the available strategies for the naïve realist to address the phenomenological problem. I argue that however the naïve realist responds to the problem she is left with a view that is distinctly unappealing if there is a version of the content view that provides a unified account of the phenomenological directness of both veridical and hallucinatory experiences. Finally, in $\$ 4 \mathrm{I}$ describe a version of the content view that I maintain provides a fully satisfactory and unified account of the phenomenological directness of both veridical and hallucinatory experiences.

\section{Naïve Realism and the Content View}

Naïve realism and the content view are competing theories of the structure of (at least certain kinds of) perceptual experiences. An experience is a particular phenomenally conscious mental state or event—one which 
is like something for its subject. The phenomenal character or phenomenology of an experience is what the experience is like for the subject. We make judgments about phenomenology by relying on the special firstperson access we have to our own experiences. Accordingly, different kinds of experiences can be distinguished from one another on the basis of their phenomenology. For instance, I know from first-person reflection on my experiences that what it's like for me to be thinking about the moon is different from what it's like for me to visualize seeing the moon; and I know that what it's like for me to visualize seeing the moon is different from what it's like for me to visualize seeing the sun.

Perceptual experiences are those experiences characteristic of the different sense modalities that at least ostensibly involve the presentation of physical things and their properties. ${ }^{3}$ Such experiences come in three types. An accurate or veridical perceptual experience is one where the things perceived have precisely the properties they are perceived to have. An illusory perceptual experience (or, more simply, an illusion) is one where the things perceived do not have all the properties they are perceived as having. And a hallucinatory perceptual experience (a hallucination) is one where at least some of the things that from the subject's point of view seem to be perceived are not in fact perceived.

Naïve realism is not a theory of every type of perceptual experience; at most it is a theory of veridical experiences and illusions, and typically it is restricted to veridical experiences alone. Restricted to veridical perceptual experiences, naïve realism is the view that to have such an experience is to stand in a primitive relation of awareness or acquaintance to some particular physical thing and its properties. ${ }^{4}$ As such, the naïve realist maintains that veridical perceptual experiences are world-involving in a strong sense. For instance, suppose you visually perceive a book with a blue cover on a table immediately in front of you. According to the naïve realist, your perceptual experience consists in your standing in the relation of acquaintance to the particular book in front of you and the blueness of its cover. As the particular book and its blueness are constituents of this relational state of affairs, they are constituents of your perceptual experience. Moreover, that you have this experience entails that the particular book exists and that

3 An important consequence of this use of the terminology is that there will be, for instance, visual experiences that are not visual perceptual experiences (more on this point below). See Siegel (2010, 24-26).

4 Alternatively, naïve realism can be defined as the view that the phenomenology of a veridical perceptual experience is constituted by the perceiver standing in a relation of acquaintance to particular physical things and their properties. See, for example, Campbell (2002, 114-15), Hellie (2007, 264-65), Fish (2009, 14-15), and Nudds $(2009,335)$. Substituting this definition would make no difference to the arguments that follow. 
you are acquainted with it and its blueness. In other words, every veridical experience is veridical by its very nature.

Conversely, the content theorist says that when one perceives one is related to the world in virtue of being the subject of a mental state or event that represents the world to be a certain way. A representational mental state or event is one with a representational content; its content is the way the state or event represents the world as being. Paradigmatic examples include beliefs and desires. For instance, the content of my belief that the book is on the table is that the book is on the table. The content theorist says that my perceptual experience of the book on the table also has the content that the book is on the table. ${ }^{5}$ The content theorist's principal claim, then, is that to have a perceptual experience is to be the subject of a representational mental state or event.

What it means for a mental state or event to have a representational content can be explained more precisely by appealing to a standard account of propositional attitudes. According to this account, regarding mental states such as beliefs and desires, the representational content of the state is a proposition and the attitude is a relation to that proposition. So, for instance, for me to believe that the book is on the table is for me to stand in the belief-relation to the proposition that the book is on the table; and for me to desire that the book is on the table is for me to stand in the desire-relation to that same proposition. Similarly, the content theorist claims that to have a perceptual experience of the book on the table is to stand in what we could call the perceptually-experiencing-relation to the proposition that the book is on the table. That is, the content theorist claims that perceptual experience is a unique kind of propositional attitude. ${ }^{6}$ Moreover, the content theorist claims that, just as a true belief is true in virtue of the fact that the proposition that constitutes its content is true, a veridical perceptual experience is veridical in virtue of the fact that the proposition that constitutes its content is true. When the proposition that constitutes the content of a given perceptual experience is false, the relevant experience is an illusion or hallucination.

How a perceptual experience's representational content is related to its phenomenology is a controversial subject amongst content theorists. I will make the minimal assumption that for any given normal subject

5 This is of course only part of the content of such an experience. Since perceptual contents are typically enormously complex the discussion will always be restricted to some specific aspect of a given content.

6 Similar accounts of the content view are presented by Thau $(2002,74)$, Johnston (2004, 176-77n.4), Byrne (2009, 437-38), and Pautz (2009, 492; 2010, 257-59). Siegel (2010, chap. 2) presents a weaker version of the content view that she claims is consistent with naïve realism; she calls the view described above the "Strong Content View." For an argument in favour of preferring the stronger characterization, see Pautz $(2009, \S 1)$. 
in a given environment, if any two of that subject's perceptual experiences possess different general representational contents then those experiences differ with regard to their phenomenology. ${ }^{7}$ In other words, I assume that the way your perceptual experience represents the world to be affects the phenomenology of your experience. For instance, the fact that your visual experience represents that the book is directly in front of you makes a difference to what that experience is like for you. If you were to have another visual experience that represented the book to be slightly off to the left, you would find when you reflected on that experience that what it was like for you was different from your previous experience of the book.

\section{Phenomenological Directness}

Both the naïve realist and the content theorist can and should accept that veridical perceptual experiences possess that feature I'm calling phenomenological directness. Very many philosophers who disagree about many different fundamental issues surrounding the nature of perception nonetheless agree that, from the first-person perspective, when you enjoy a veridical perceptual experience physical things and their properties seem to be directly present to you. ${ }^{8}$ This much, then, can be taken for granted: our veridical perceptual experiences all possess a phenomenology of direct presence that none of our non-perceptual experiences possess. In addition, many philosophers (including most of those mentioned in the previous footnote) assume that hallucinations also possess this distinctive phenomenology. After describing phenomenological directness in greater detail, I'll discuss the reasons that support the assumption that hallucinations possess this phenomenological feature.

\subsection{Object-Immediacy and Object-Distinctness}

There are two aspects of the phenomenological directness of perceptual experience that are not always carefully distinguished. Consider Strawson's claim again that perceptual experience seems to be "an immediate consciousness of the existence of things outside us." There are two

7 This claim is restricted to general contents since a content theorist might claim that perceptual contents constitutively involve particular objects, times or locations, and that it's possible for experiences with contents involving distinct particulars to be phenomenologically identical. See, for example, Speaks (2009).

8 Hellie $(2007,266)$ produces a list of quotations of philosophers calling attention to this phenomenological feature; in addition to the quotation from Strawson reproduced above, the list includes quotations from Broad, McDowell, Sturgeon, and Levine. Some further examples: Husserl (1900/1970, 712), Searle (1983, 45-46), Alston (1999, 182), Smith (2002, 43), Crane (2006, 134), Hellie (2007, 268), and Fish $(2009,4)$. 
closely connected phenomenological points being made here. First, Strawson is noting that the objects of perception seem to be presented immediately or directly to consciousness. Second, Strawson is noting that the objects of perception are presented as "things outside us." In other words, the things that seem to be immediately present to us in perception seem to be distinct or separate from our consciousness. Strawson's statement thus highlights that there are in fact two different phenomenological features that make up the distinctive phenomenology of perceptual experience.

The distinction between these two features can be clarified by contrasting perceptual experience with other kinds of experience. First, it is typical to isolate the phenomenology of direct presence by contrasting perceptual experience with conscious thinking and imagining. ${ }^{9}$ For instance, compare visually perceiving that there is a book on the table in front of you with thinking or visualizing that there is a book on the table in front of you. When you see the book there seems to be some kind of direct contact between your mind and the book that is missing when you merely think that the book is in front of you or visualize seeing the book in front of you. That is, when you see it, the book itself seems to be simply revealed to your consciousness; the book itself does not seem to be present to your mind in this same way when you merely think about or visualize it. Modifying some terminology from Sturgeon (2000, chap. 1) I will call this phenomenological feature of perceptual experience object-immediacy.

Second, we can isolate the phenomenological distinctness or separateness of the objects of perception by contrasting perceptual experience with brute sensation. For instance, consider the light and dark fuzz you experience when you close your eyes, or the coloured "phosphenes" you experience when you press on your closed eyes for a while. ${ }^{10}$ Such visual experiences possess object-immediacy. When you have an experience of some particular phosphene that phosphene itself seems to be directly present to your consciousness in a way that it would not were you to merely think about or visualize it sometime later. However, when you have a visual experience of a phosphene you do not seem to be presented with something that has an existence separate from that very experience of it; rather the phosphene seems to be merely some aspect of what it's like for you to have the experience.

9 See, for example, Searle (1983, 45-46), Alston (1999, 182), Sturgeon (2000, 27), Smith (2002, 43), Crane (2006, 139), and Hellie (2007, 268).

10 The visual experience you enjoy when your eyes are closed is given as an example of brute sensation by Smith $(2002,129)$ and Siegel $(2010,24)$. Phosphene experiences are discussed by Block (1996, 35), Smith (2002, 129-30) and Siegel (2006, 372). 
Conversely, when you visually perceive a physical thing like a book, you seem to be presented with something that is distinct from that very experience of it. I will call this phenomenological feature of perceptual experience object-distinctness.

Neither object-immediacy nor object-distinctness alone is unique to perceptual experience. As I've just said, brute sensations possess objectimmediacy; and since the objects of any given episode of thinking or imagining seem to be distinct from the relevant conscious episode, such experiences possess object-distinctness. What is distinctive of perceptual experience, then, is the combination of these phenomenological features. When you have a perceptual experience it seems to be the case that something distinct from your consciousness is immediately present to your consciousness; the same is never true when you are merely thinking, imagining, or enjoying a brute sensation. (I will continue to use "phenomenological directness" to refer to the conjunction of these two phenomenological features, and "object-immediacy" and "objectdistinctness" to refer to them individually).

\subsection{Hallucinations}

It's common to assume that, just like veridical experiences, hallucinations are phenomenologically distinct from thinking, imagining, and brute sensation in the ways just described - that they possess phenomenological directness. I find this assumption extremely intuitively plausible, but it will be helpful to outline the reasons that support the assumption since some naïve realists reject it (see $\S 3$ below).

There are at least two powerful reasons for thinking hallucinations possess the phenomenology at issue. First, first-person reflection on the character of hallucinations typically produces the belief that hallucinations possess the same phenomenological directness that veridical experiences possess. If you enjoy a full-blown hallucination and reflect on what the experience is like you will find that, unlike consciously thinking or imagining, it's as though some object itself seems to be immediately present to you. In addition, you will find that, unlike a brute sensation, the object that seems to be immediately present to you seems to be something that exists apart from your experience of it. A much larger proportion of the population suffers hallucinations than is often assumed, and many affected individuals are such that we have no particular reason to doubt their powers of introspection. ${ }^{11}$ Moreover, the nature of the introspective task at issue-distinguishing the phenomenology of experiences as different as thinking, imagining and

See, for example, Tien (1991), Ohayon (2000), and Aleman and Larøi (2008, 61-69). 
perceiving - is not particularly demanding. ${ }^{12}$ Consequently, those of us who have experienced hallucinations have introspective evidence that they possess the relevant phenomenology and this evidence ought to be accorded a great deal of weight (after all, our knowledge that veridical experiences possess phenomenological directness is based on introspection).

Second, there has been a great deal of scientific study of hallucinations and the best explanation of the facts revealed by this research is that hallucinations possess phenomenological directness. Researchers who study hallucinations typically define them in part as experiences that are distinct with respect to their conscious character from thinking, imagining and brute sensation. For example, in an influential paper Aggernaes $(1972,222)$ claims that hallucinations possess a "quality of sensation" that distinguishes them from thinking and imagining; and he claims that hallucinations possess a "quality of existence" in the sense that it seems to the subject that the object of the experience "also exists when nobody experiences it at all" $(1972,226)$. Slade and Bentall try to capture both of these "qualities" in their definition by stating that a hallucination is "a percept-like experience having the full force and impact of an actual perception" $(1988,24)$. And perhaps most frequently, these phenomenological features are captured by the characterization of a hallucination as an experience with a "sense of reality" comparable to that of a veridical perceptual experience. ${ }^{13}$ For present purposes, the importance of such definitions is that researchers have identified large numbers of subjects suffering from a wide range of psychological and physiological disorders - conditions as different as blindness and schizophrenia - that report having experiences that satisfy the standard definition of hallucination. ${ }^{14}$ That is, large numbers of individuals claim to have perceptual experiences possessing phenomenological directness in the absence of appropriate stimuli.

In addition to the self-reports of such individuals (and other behavioural evidence), a great deal has been learned about hallucinations by

12 I should emphasize that I'm not claiming that a given veridical perceptual experience and a "matching" hallucination are indiscriminable from one another or are phenomenologically exactly alike. My claim is considerably weaker: I maintain only that hallucinations are like veridical experiences in that they are phenomenologically distinct from conscious thoughts, imaginings, and brute sensations in the ways described above.

13 For an overview of the different definitions of "hallucination" that have been provided in the scientific literature see Aleman and Larøi (2008, 15-17). For discussion see Farkas (forthcoming).

14 For an overview see Slade and Bentall (1988, chap. 2) and Aleman and Larøi (2008, chap. 3). 
using various neuroimaging techniques. ${ }^{15}$ In particular, research has shown that those parts of the brain that are active during conscious perception in a particular modality are also active when a subject claims to be hallucinating in that same modality, and that brain activity varies depending on the content of the reported hallucination. For instance, ffytche et al. (1998) found that the brain's colour center was active in those subjects who claimed to hallucinate in colour and was not active for a subject who claimed to hallucinate in black-and-white. The same study also found activity in an area of the brain known to respond to the presentation of unfamiliar faces in a subject who claimed to hallucinate seeing an unfamiliar face. Research of this sort has established that the brain activity that correlates with hallucinatory experiences is similar to that which correlates with conscious perception in important ways, and is distinct from the activity that correlates with thinking and imagining. ${ }^{16}$

Taken together, it's clear that the best explanation of the self-reports of hallucinators and the brain imaging data is that hallucinations possess phenomenological directness. If you wanted to deny that hallucinations possess the phenomenology at issue you would have to explain why so many hallucinators make claims to the contrary; and given the wide range of conditions that give rise to hallucinations, presumably you would have to come up with different explanations for different kinds of hallucinators. In addition, you would have to explain why the activity in hallucinating brains which, given our knowledge of the correlations between certain kinds of brain activity and certain kinds of experience, we would expect to correlate with experiences possessing phenomenological directness, is present in the absence of such experiences; and presumably such an explanation would require making significant revisions to well-established neuroscientific theories. Conversely, by assuming that hallucinations possess phenomenological directness we explain straightforwardly why individuals claim that their hallucinatory experiences are unlike thinking, imagining, or enjoying brute sensations, and why brain activity known to correlate with conscious perception is observed in hallucinating brains.

\section{Naïve Realism and the Phenomenological Problem}

Given that phenomenological directness is the distinctive feature of perceptual phenomenology, a theory of perception that provides a

\footnotetext{
15 For an overview see Aleman and Larøi (2008, 154-69).

16 For instance, the differences between brain activity correlated with hallucination and that correlated with imagery are stressed by ffytche et al. $(1998,740)$, Woodruff $(2004,83-84)$, and Oertel et al. $(2007,272)$.
} 
satisfying account of why perceptual experiences possess this phenomenology has a significant advantage over any rival theory that fails to provide such an account. Many philosophers have been attracted to naïve realism precisely because it seems to have the resources to explain the phenomenological directness of at least veridical perceptual experiences. But the naïve realist's account of the phenomenological directness of veridical experiences can't be extended to explain why hallucinations possess this phenomenological feature. In and of itself, this fact isn't a reason to reject naïve realism; but if some alternative theory were available that provided a better solution to the phenomenological problem, then we would have a compelling reason to prefer it to naïve realism. The point to be established in the present section, then, is that every response to the phenomenological problem available to the naïve realist leaves her with a view that is distinctly unappealing if we can find a variety of the content view that provides a unified account of the phenomenological directness of both veridical experiences and hallucinations. Accordingly, I will first briefly describe the naïve realist's account of the phenomenological directness of veridical perceptual experiences and explain why it can't be applied to hallucinations; then I will review the naïve realist's options for handling the phenomenological directness of hallucinations and explain why each is problematic.

\subsection{Naïve Realist Accounts of Phenomenological Directness}

I assume that what it means for a theory of perception to provide an account of the phenomenological directness of perceptual experience is for the phenomenology to "fall out" of the theory. A theory of perception is a proposal about the structure of perceptual experiences; if some feature of the proposed structure is sufficient for the relevant phenomenology, then the theory provides an account of why perceptual experiences possesses this phenomenology. Since the naïve realist claims that to have a veridical perceptual experience is to stand in a relation of acquaintance to particular physical things and their properties, we may assume that a naïve realist account of phenomenological directness will appeal to either the position of particular physical things in the structure of veridical experience or the special nature of the relation of acquaintance.

First, according to naïve realism veridical perceptual experiences are world-involving in a strong sense and some defenders of the view maintain that it's this feature of perceptual experience that suffices for phenomenological directness. For instance, Crane maintains that naïve realism best captures the "apparent relationality" of perceptual 
experience because according to this view "perceiving an object is an essentially relational state, of which the object perceived is a constituent; so the perception is constitutively dependent on the object perceived" $(2006,140) .{ }^{17}$ In other words, according to this proposal, having a physical object as a constituent is sufficient for an experience to possess phenomenological directness; and since according to naïve realism the structure of veridical perceptual experiences is such that they have physical objects as constituents, naïve realism explains why such experiences possess phenomenological directness.

Alternatively, a naïve realist might explain why veridical experiences possess the relevant phenomenology by appealing to the relation of acquaintance. According to naïve realism, to perceive is to stand in a primitive, non-representational mental relation to physical things and their properties; and a defender of the view might claim that standing in this primitive, non-representational mental relation to some physical thing suffices for phenomenological directness. For instance, Sturgeon characterizes the naïve realist's reasoning along just these lines. "The idea," he says, "is that brute contact [or acquaintance] makes it for the subject as if a public object and its features are directly before the mind" $(2000,12)$.

Whether either of these purported explanations ultimately succeeds is open to dispute; but for present purposes I will grant that at least one of the features just described suffices for phenomenological directness and that, consequently, the naïve realist has a satisfactory account of why veridical experiences possess this phenomenology. The important point is that neither of these two potential accounts of the phenomenological directness of veridical perceptual experiences can be applied to the phenomenological directness of hallucinations. The difficulty, of course, is that neither of the features of veridical perceptual experiences that a naïve realist might claim suffices for phenomenological directness is a feature of hallucinations. The naïve realist who appeals to the fact that veridical experiences have physical objects as constituents can't explain the phenomenological directness of hallucinations this way, because in the case of a hallucination there is no appropriate object to serve as a constituent of the experience. And the naïve realist who appeals to the fact that veridical experiences involve standing in a relation of acquaintance to some physical object can't explain the phenomenological directness of hallucinations this way, because in the case of a hallucination there is no appropriate object to which to stand in the relevant relation. 


\subsection{Naïve Realism and Hallucinations}

Given that the naïve realist's account of the phenomenological directness of veridical perceptual experiences can't be applied to hallucinations, then, what should the naïve realist say regarding the phenomenological directness of hallucinations? That is, how can the naïve realist respond to the phenomenological problem? There would seem to be only three available options and each involves adopting some form of disjunctivism - roughly, the view that veridical perceptual experiences are unlike hallucinations (and illusions as well, on some views) in important mental respects. ${ }^{18}$ First, the naïve realist can simply deny that hallucinations possess the phenomenological feature at issue. Second, he can grant that hallucinations possess this phenomenology but refuse to give any account of this fact. And third, he can provide an account of the phenomenological directness of hallucinations that is distinct from his account of the phenomenological directness of veridical experiences.

A negative disjunctivist will embrace the first option and deny that hallucinations possess phenomenological directness. For example, Martin $(2004 ; 2006)$ claims that while both veridical perceptual experiences and hallucinations possess phenomenal character, there is no more specific phenomenological feature that they share. ${ }^{19}$ And Fish (2009, chap. 4) goes further still by claiming that hallucinations lack phenomenal character altogether. The difficulty with this strategy is that we have very good reasons for thinking that hallucinations possess the same phenomenology that distinguishes veridical experiences from conscious thinking, imagining, and brute sensation. To claim otherwise is to deny the evidence of introspection and reject what is clearly the best explanation of the facts revealed by the scientific study of hallucinations (see \$2.2). Consequently, any view that accepts the claim that hallucinations possess phenomenological directness will have a significant advantage over a naïve realist view that denies it.

Some positive disjunctivists will embrace the second option and grant that hallucinations possess phenomenological directness while refusing to give an account of this fact. For instance, Langsam (1997) maintains that naïve realism is principally a theory of the nature of veridical perceptual experiences and, as such, the naïve realist is entitled to remain agnostic about the nature of hallucinations. More specifically, he says

18 For discussion of the central tenets of disjunctivism and the distinction between negative and positive disjunctivism employed below, see Byrne and Logue (2008, 57-72) and Pautz (2010, 260-65).

19 Martin restricts this claim to what he calls "causally matching hallucinations" but since this restriction makes the claim at issue even less plausible, I will ignore it. Campbell (2002, chap. 6) professes a similar view. 
that while naïve realism should acknowledge that hallucinations have an "ontological character" distinct from that of veridical experiences, "it need not commit itself to any particular account of the ontological character of hallucination" $(1997,146)$. The difficulty with this strategy is just that, all else being equal, a theory that explains more relevant facts is preferable to a theory that explains fewer such facts. Consequently, a theory that provides an account of the phenomenological directness of both veridical experiences and hallucinations will have a significant advantage over a naïve realist theory that says nothing about why hallucinations possess this phenomenology.

Finally, other positive disjunctivists will embrace the third option and provide a separate account of the phenomenological directness of hallucinations. The naïve realist who adopts this strategy must provide an account of the structure of hallucinations, and some feature of this proposed structure must be sufficient for the relevant phenomenology. There are any number of different possibilities. To mention just two: the naïve realist might claim that to hallucinate is to stand in a relation of acquaintance to sense-data and that standing in this relation to sense-data suffices for phenomenological directness; or he might claim that to hallucinate is to be the subject of a mental state with representational content and that being in such a state suffices for phenomenological directness. ${ }^{20}$ In addition, as Hellie (forthcoming) notes, the naïve realist might claim that different kinds of hallucinations possess different structures.

One significant difficulty with this strategy is that it risks undermining the naïve realist's account of the phenomenological directness of veridical perceptual experiences. Whatever feature of hallucinations the positive disjunctivist claims suffices for phenomenological directness, there may be reasons to think that this feature is also a feature of veridical experiences; and if so, then one could abandon the naïve realist account, still explain the phenomenological directness of veridical experiences, and ultimately end up with a far simpler explanation of why experiences possess this phenomenology. ${ }^{21}$ However, even if the naïve realist can produce an account of the phenomenological directness of hallucinations that does not undermine his original account in this way, the resulting view will necessarily be a complicated, disunified account of why perceptual experiences possess phenomenological directness. And since, all else being equal, unified explanations are pref-

20 For discussion of these and other possibilities, see Byrne and Logue (2008, 63-65) and Pautz (2010, 262-65).

21 Martin (2004) emphasizes this point. For discussion of how the naïve realist might respond to these kinds of concerns see Pautz (2010, 298-99) and Hellie (forthcoming). 
erable to disunified explanations, a theory that provides a unified account of the phenomenological directness of both veridical experiences and hallucinations will have a significant advantage over a naïve realist theory that provides a separate account of each. ${ }^{22}$

Each of the naïve realist's options for handling the phenomenological directness of hallucinations, then, is problematic; that is, every possible naïve realist solution to the phenomenological problem has considerable difficulties. Even so, some naïve realist solution to the phenomenological problem might be the best solution available-particularly if the most plausible rival theory of perception, the content view, doesn't provide a satisfactory account of phenomenological directness at all. However, if some variety of the content view can explain the phenomenological directness of perceptual experiences, and if this theory can provide a unified account of the phenomenological directness of both veridical and hallucinatory experiences, then this theory's account would be preferable to any naïve realist account for the reasons just outlined. In the next section I describe a theory of just this sort.

\section{The Content View and the Phenomenological Problem}

In order for the content view to provide an account of the phenomenological directness of perceptual experiences it must be the case that some feature of the structure of perceptual experiences as understood by the theory suffices for this phenomenology. Very many representational mental states and events lack the phenomenological directness that characterizes perceptual experiences; so the defender of the content view will have to identify some feature of the purported structure of perceptual experiences that they do not share with other representational states or events. And since according to the content view, perceptual experience is a special sort of propositional attitude, the content theorist basically has two options: first, appeal to the special nature of the relevant attitude (the perceptually-experiencing-relation) or, second, appeal to the special nature of the propositions that constitute the contents of perceptual experiences.

The first option is problematic because the content theorist can't specify the special attitude perceptual experiences involve except to say that it's that attitude which suffices for phenomenological directness. That is, the content theorist has no grasp of what distinguishes the perceptually-experiencing-relation from the belief-relation or the desire-

22 This sort of complaint is frequently directed at positive disjunctivism. See, for example, Sturgeon (2000, 10), Pautz (2010, 299-301), and Vega-Encabo (2010, 288). 
relation, except that standing in the former to a proposition suffices for phenomenological directness while standing in any other such relation to a proposition does not. As a result, while the content theorist who appeals to the special attitude perceptual experiences involve can certainly identify a feature of the purported structure of perceptual experiences that suffices for phenomenological directness, that feature can't be specified without appealing to the very phenomenology at issue. ${ }^{23}$ Such an account of phenomenological directness would thus be circular; and if we grant that the naïve realist has a non-circular account of the relevant phenomenology, then the present proposal would leave the content view at a significant disadvantage relative to naïve realism. ${ }^{24}$

Alternatively, the content theorist might be able to provide an account of phenomenological directness by appealing to the special nature of the representational contents that perceptual experiences involve. That is, the content theorist can maintain that perceptual experiences are phenomenologically distinct from conscious thoughts, imaginings, and brute sensations, not in virtue of involving a unique attitude, but in virtue of involving unique representational contents. If the relevant representational contents can be specified without appealing to phenomenological directness, then the content theorist can provide a non-circular account of this phenomenology.

The most promising approach to identifying what distinguishes perceptual experiences from other kinds of experiences, I believe, is to appeal to the representation of the causal relation between the object of perception and the perceiver. Searle's (1983, chap. 2) proposal regarding the content of perceptual experiences is a well-known example of such a view. I maintain that while Searle's view cannot provide a satisfactory account of the phenomenological directness of perceptual experience as it stands, an appropriately modified version of his view can. Moreover, I maintain that this view explains the phenomenological directness of both veridical and hallucinatory experiences in a unified way. After describing the difficulty facing Searle's view, I will explain how the modified version provides a satisfying account of the

23 Chalmers (2004), Pautz (2007, 519) and Schellenberg (2011) all provide accounts of the distinctive phenomenology of perceptual experiences along these lines. Brewer $(2011,56)$ complains that it's particularly unilluminating for the content theorist to appeal to the special perceptual attitude in this context.

In fact, it's not obvious that the naïve realist can specify the feature of the purported structure of perceptual experience that suffices for phenomenological directness without appealing to the very phenomenology at issue (as Sturgeon [2000, 13-14] complains). However, I ignore the difficulty since I believe that the version of the content view outlined below provides a non-circular account of the phenomenology which is therefore preferable to even a non-circular naïve realist account (as well as any circular representational account). 
phenomenological directness of perceptual experiences; I will then explain how this account applies to hallucinations in particular. (Since the content view is often assumed to have special difficulty explaining the phenomenological difference between perceptual experience and conscious thought or imagination, I begin by focusing on how the content view can provide an account of object-immediacy, and later touch on object-distinctness more briefly).

\subsection{Searle's View}

Searle claims that when you have a visual perceptual experience of a particular object in a particular location, your visual experience represents that an object's being in a certain location is causing that very experience. For example, Searle claims that when you have a visual experience of a particular yellow station wagon, the content of your experience is "that there is a yellow station wagon there and that there is a yellow station wagon there is causing this visual experience" $(1983,48)$.

Searle's principal motivation for including the causal relation between the object of perception and the perceptual experience in the content of that very experience is to account for the fact that a visual perceptual experience of a given object is veridical only so long as an object in the relevant location is causing that experience (1983, 47-49). However, Searle also provides a phenomenological argument for his view: he maintains that his proposal regarding perceptual content explains the phenomenological difference between visual perceptual experience and other kinds of experience, in particular visualization. For instance, Searle asks what would be responsible for the phenomenological difference between visualizing your house in an extremely vivid manner and having an ordinary visual experience of your house. His answer is that "the voluntarily formed images we would experience as caused by us, the visual experience of the house we would experience as caused by something independent of us. The difference in the two cases is a difference in the causal content of the two experiences" $(1983,124 n){ }^{25}$

While I believe that this proposal is on the right track, as it stands Searle's view can't provide an account of the phenomenological difference between perceptual experience and other kinds of experience. Specifically, while Searle's view explains the phenomenological difference between perceptual experience and imagination, it can't explain the phenomenological difference between perceptual experience and conscious thought. The difficulty with his proposal is that a thought about a particular object can represent that the relevant object is causing

Searle $(1991,184)$ makes the same point about the phenomenological difference between perceptual experience and other kinds of experience. 
that very thought, but such a thought would still lack object-immediacy. For instance, when I notice the book on the table I can consciously think that there is a book on the table and that there is a book on the table is causing this very thought; but this thought will not seem to make the book itself present to me in the way that my visual experience does. Consequently, since representing the object of an experience to be causing that very experience is not sufficient for object-immediacy, this feature of Searle's picture of perceptual experience would not furnish the content view with an account of object-immediacy.

\subsection{The Direct Causal Content View}

Searle's proposal can't account for the phenomenological difference between perceptual experiences and thoughts because a thought can have the content that the thought-of object is causing that very thought. That is, merely representing that the experience is caused by some object would not distinguish perceptual experience from every other kind of experience. However, the way in which physical things are causally related to veridical perceptual experiences is distinct from the way in which they are causally related to every other kind of experience.

There are two unique features that are particularly important for present purposes. First, when there is a causal connection between a conscious thought about (or an episode of imagining) a particular physical object and that object, that causal connection always involves the mediation of some distinct experience. For instance, the causal chain connecting my conscious thought about the book on the table to the book always involves some distinct conscious experience-before I can have my conscious thought about the book I first have to perceive the book itself, or hear someone talk about the book, or something of the sort. Conversely, the causal connection between a veridical perceptual experience of a given object and that object never involves the mediation of some distinct experience-I never, for instance, have a conscious thought of the book that then generates a veridical visual experience of the book.

Second, a veridical perceptual experience of a given object is only ever caused automatically (in the sense that the experience could not have been precipitated and cannot be terminated by the exercise of the subject's will) by a causal link to the (approximately) present state of that object. ${ }^{26}$ For example, I only ever have a veridical visual experience of the book on the table when light that it has just now reflected

26 When the perceiver is not causally connected to the (approximately) present state of the thing perceived, a non-veridical perceptual experience results. For example, your auditory experience of thunder is illusory in that it sounds like something that occurs some time after lightning has struck. 
impacts my retinas, and the resulting experience is not something I can voluntarily put an end to so long as this causal connection persists. Conversely, a conscious thought about (or episode of imagining) some particular physical object is typically under the voluntary control of the subject and does not require a causal link between that thought and the present state of the object. For instance, when I see that the book is on the table and then close my eyes I am still able to consciously think that the book is on the table as a result of the causal connection between that thought and the state the book was in a few seconds ago. And even when there is a causal connection between the present state of the book and my conscious thought about it, that thought is something that I could have brought about at will and can put an end to voluntarily (for instance, by deciding to think about something more interesting).

When an experience is caused by some physical thing such that, first, the causal connection between them does not involve the mediation of some distinct experience and, second, the experience is generated automatically by a causal link to the present state of the relevant physical thing, I will say that the experience directly causally depends on that physical thing. ${ }^{27}$ So, for instance, my visual experience of the book on the table directly causally depends on the book, but my conscious thought about the book does not.

This point about the special nature of the causal relation between a veridical perceptual experience and the object of the experience suggests that modifying Searle's proposal regarding perceptual content to include direct causal dependence would furnish the content view with an account of object-immediacy. Specifically, the content theorist can claim that a perceptual experience doesn't represent merely that some object is causing that very experience, but rather that the experience directly causally depends on some object. So, for instance, when I have a visual perceptual experience of the book on the table, the experience represents (in part) that this experience directly causally depends on the book's being on the table. According to the present proposal, then, what is unique about perceptual experiences is that the unique causal relation that such experiences stand in to perceived objects is a constituent of the proposition that constitutes a perceptual experience's representational content. ${ }^{28}$ I will call the view that perceptual experiences possess such contents the direct causal content view.

27 I am using "direct causal dependence" merely as a label for causal relations that exhibit the two features just described. In the arguments that follow I do not intend to be appealing to any commonly used notion of direct causation.

28 For the sake of simplicity, I'm assuming that perceptual contents are general Russellian propositions. I will say more about this assumption in $\$ 4.3$. 
Unlike the representation of causal relations as such, the representation of direct causal dependence would seem to be sufficient for objectimmediacy. In particular, the direct causal content view succeeds precisely where Searle's view fails. When I notice the book on the table and consciously think that there is a book on the table, I am aware that this thought about the book is causally mediated by my visual experience of the book. Moreover, I am aware that my thought that the book is on the table is not caused automatically by a causal link between my thought and the present state of the book-for instance, I am aware that whether or not I consciously think about the book being on the table is something I can typically control. So, while I can consciously think that there is a book on the table and that there is a book on the table is causing this very thought, I cannot consciously think that there is a book on the table and this very thought directly causally depends on the book's being on the table. Of course, I can consciously entertain or grasp the latter proposition, but I can't think that this proposition is true. That is, I can't voluntarily adopt the kind of attitude toward this proposition that involves the sort of commitment that is present in belief and perceptual experience and absent from merely grasping or considering some proposition. ${ }^{29}$

In addition, there are two thought experiments that I believe will help motivate the claim that the representation of direct causal dependence accounts for the fact that our perceptual experiences possess object-immediacy. First, I've just noted that I can't consciously think that some particular thought directly causally depends on the object of that very thought, and presumably this is true of every human being. But one might wonder whether beings that have such thoughts are possible. For instance, we might imagine a special superblindsighter who has no visual perceptual experience of any kind, but who has accurate conscious thoughts about objects in her environment which are produced automatically when the light reflected by those objects stimulates her retinas. ${ }^{30}$ Imagine that when this superblindsighter looks at, for example, a book on a table, part of the content of her resulting conscious thought is that that very thought is caused without the mediation of any distinct experience by the book's being on the table. Imagine also that it is part of the content of her thought that this thought is produced by a causal connection between it and the present state of the book and by a process over which she has no conscious control (it may also help to imagine that the contents of this individual's conscious thoughts when looking at a given object are every bit

This notion of commitment is discussed, for instance, by Siegel $(2010,49-50)$.

30

For discussion of superblindsight, see Block $(1995,233)$ and Siewert (1998, 76-84). 
as detailed as the contents of normal human visual experiences). If the representation of direct causal dependence is sufficient for objectimmediacy, then this superblindsighter's conscious thoughts about the objects impacting her sense organs ought to possess object-immediacy; and, in fact, I believe it's plausible to claim that they would. For instance, given that this superblindsighter's thought that the book is on the table seems to her to be caused without the mediation of any distinct experience by the book being on the table and seems to her to be the automatic result of a causal link between her thought and the book presently being on the table, it's plausible to suppose that her thought would seem to her to be a purely intellectual yet nonetheless immediate awareness of the book being on the table. That is, it's plausible to suppose that the special kind of thought she has when looking at the book would make the book itself seem to be present to her in a way that thoughts she might have about the book when it was out of view would not.

Second, consider what it would be like to have an experience that was as phenomenologically similar to a perceptual experience as possible while seeming not to directly causally depend on a given object. For instance, imagine you had the ability to voluntarily reproduce a perceptual experience after it was over-to re-live the experience, perhaps by spontaneously generating the crucial neural activity. Imagine, however, that when you reproduced the original experience you were aware that the causal connection between your present experience and the object of the experience was mediated by the original perceptual experience. Imagine also that when you reproduced an experience you were aware that your resulting experience was not generated automatically by a causal link between that experience and the present state of the relevant object, but rather was generated voluntarily and causally connected to some past state of that object. If the representation of direct causal dependence is what accounts for the fact that our perceptual experiences possess object-immediacy, then such an experience ought to lack object-immediacy (assuming no remaining feature suffices for object-immediacy); and, in fact, I believe it's plausible to claim that it would. For instance, it's plausible to think that if you reproduced a visual experience of the book on the table that it would not seem to you as though the book itself were present to you in the way it seemed to be when you had your original visual experience of the book. Rather, it's plausible to think that such an experience would seem like an extremely vivid memory of seeing the book on the table.

If the foregoing is correct, then the defender of the direct causal content view has a satisfactory account of object-immediacy. The crucial feature of this theory of perceptual experience is that having a perceptual 
experience is a matter of standing in the perceptually-experiencing-relation to a special kind of content-one that includes that the experience directly causally depends on the apparent object of the experience. As we've seen, it's quite plausible that any commitment-involving propositional attitude that possesses such a content will possess objectimmediacy. So, the direct causal content theorist's picture of perceptual experience has a feature that suffices for object-immediacy.

If, then, that feature of perceptual experience that the direct causal content theorist claims suffices for object-immediacy also suffices for object-distinctness, then this theory has an account of the phenomenological directness of perceptual experience. And I think it's evident that standing in the perceptually-experiencing-relation to the relevant kind of content does indeed suffice for object-distinctness. Remember that object-distinctness is what distinguishes perceptual experiences from brute sensations. If we assume that brute sensations lack representational contents altogether, then possessing any sort of representational content suffices for object-distinctness. But even if Siegel $(2006,374)$ is correct that brute sensations possess representational contents, the direct causal content theorist can claim quite plausibly that no brute sensation represents that it directly causally depends on a given object. It should be clear, for instance, that when you have an experience of some particular phosphene that your experience does not represent that the phosphene causes the experience without the mediation of any distinct experience or that it is caused automatically by a causal link between the experience and the present state of the phosphene. When you have such an experience the phosphene doesn't seem to be the kind of thing that one has an experience of thanks only to a contingent causal connection; the phosphene seems to be merely some aspect of your experience rather than something on which your experience causally depends. ${ }^{31}$ Consequently, we may conclude that any commitment-involving propositional attitude that possesses the sort of content at issue will possess object-distinctness; and, as such, that feature of perceptual experience that the direct causal content theorist claims suffices for object-immediacy also suffices for object-distinctness. Ultimately, then, perceptual experiences as understood by the direct causal content view possess a feature that suffices for phenomenological directness. And moreover, since the notions of a commitment-involving attitude and direct causal dependence can be specified without appealing to the very phenomenology to be explained, unlike other versions

31 Siegel $(2006,379)$ denies that the possession of causal contents can be what distinguishes perceptual experiences from brute sensations, but she does not explain how the claim that brute sensations also possess such contents could be defended. 
of the content view, the present view provides a non-circular account of the phenomenological directness of perceptual experience.

\subsection{The Direct Causal Content View and Hallucinations}

Because the naïve realist's account of phenomenological directness appeals to some feature of veridical perceptual experiences that hallucinations lack, the naïve realist can't provide a unified explanation of the phenomenological directness of veridical and hallucinatory experiences. But unlike the naïve realist who must insist that the structure of veridical perceptual experiences is distinct from that of hallucinations (that is, who must adopt some form of disjunctivism), there is no particular reason why the content theorist can't claim that veridical experiences and hallucinations are the very same type of propositional attitude. A striking, much-discussed feature of propositional attitudes is that the apparent objects of such mental states and events sometimes don't exist. ${ }^{32}$ For instance, an individual can have very many beliefs about Santa Claus even though there is no such person - the fact that there is no such person doesn't stop individuals from standing in the belief-relation to Santa Claus-concerning propositions. Consequently, the content theorist may sensibly claim that a hallucination, just like a veridical perceptual experience, is a matter of standing in the perceptually-experiencing-relation to a proposition.

The direct causal content theorist maintains that standing in the perceptually-experiencing-relation to a specific sort of content suffices for phenomenological directness. So, given that there is no particular difficulty with the claim that to suffer a hallucination is to stand in the perceptually-experiencing-relation to a proposition, the direct causal content view will provide a unified account of the phenomenological directness of both veridical and hallucinatory experiences just so long as a hallucination can have the relevant sort of content. Here the crucial feature of the present view is that that feature of perceptual content that suffices for phenomenological directness is the representation that a certain specific relation obtains. That is, the direct causal content view makes no specific commitment with respect to how the object of a perceptual experience figures in the content of that experience; rather, a defender of the view maintains only that when a certain relation is included in the content of a perceptual experience, that experience possesses phenomenological directness. A hallucination, then, can have

32 This is, of course, why treating perceptual experiences as states or events with representational content has been and continues to be a popular approach to understanding hallucinations. Harman (1990) is an influential example. 
the relevant sort of content because this relation can be included in the content of a hallucinatory experience - an experience can represent that it directly causally depends on a certain object in a certain location even when there is no such object. For instance, an experience can represent that there is a book on the table and this experience directly causally depends on the book's being on the table even if there is no book on the table causing the experience.

By way of contrast, imagine a version of the content view that appealed to object-involving or singular propositions in order to explain the phenomenological directness of perceptual experiences. That is, imagine a content theorist who claimed that perceptual experiences possess phenomenological directness because the object of a given experience is a constituent of the proposition constituting that experience's content. Since in the case of a hallucination there is no appropriate object for the relevant proposition to have as a constituent, this theorist would have to find some distinct account of the phenomenological directness of hallucinations (and consequently, such a content theorist would be in no better position to provide a unified account of the phenomenology than the naïve realist). Conversely, the direct causal content view explains the phenomenological directness of perceptual experiences by appealing to the representation of a certain specific relation rather than to the representation of objects as such. As a result, both veridical perceptual experiences and hallucinations can possess that feature that the direct causal content theorist claims suffices for phenomenological directness; and thus the present view provides a unified account of the phenomenological directness of both veridical and hallucinatory experiences.

(For the sake of simplicity, I've been assuming that perceptual contents are general Russellian propositions, but the direct causal content view is compatible with any number of different views on the relationship between perceptual contents and the objects of perception. For instance, a defender of the present view could consistently claim that the object of a veridical experience is a constituent of the content of that experience as long as he had independent reasons for this claim-reasons other than to explain the phenomenological directness of such experiences. If one held this view one would have to grant that the contents of veridical perceptual experiences differed from the contents of hallucinations; but as these differences would play no role in the explanation of the phenomenological directness of such experiences, the defender of this view would still have a unified account of the relevant phenomenology. The direct causal content view is also straightforwardly compatible with Fregean views where a mode of presentation of an object rather than the object itself is a constituent of the content 
of a perceptual experience. It is also consistent with the view that experiences have multiple contents. ${ }^{33}$ In general, because perceptual contents will be expected to explain a variety of phenomena distinct from phenomenological directness, subscribing to the direct causal content view puts very few constraints on one's theorizing about the nature of such contents. ${ }^{34}$ )

\subsection{An Objection}

I won't attempt to provide an exhaustive survey of the objections that the direct causal content view is likely to face. But since philosophers have consistently complained that Searle's view makes perceptual contents too complex or sophisticated, one might be concerned that the direct causal content view seems to make perceptual contents even more sophisticated.

A first way of characterizing the complaint would be to say that the features that according to the direct causal content view are included in perceptual contents are too complex, given that cognitively unsophisticated creatures have perceptual experiences very similar to those of normal human adults. For instance, Armstrong objects to Searle's view on the grounds that it's not clear how the representational content of a dog's perceptions could "include, besides an external scene including the dog's bodily relation to that scene, the self-referential component that the perception itself, something in the dog's mind, should be caused by the external scene" $(1991,154)$. However, a dog's perceptual experiences presumably represent all kinds of very complex features. For instance, as Siegel (2006, 384) notes, a dog's visual perceptual experiences have to represent the locations of physical objects relative to the dog's present vantage point. So, given that a dog's cognitive limitations are consistent with it having experiences that represent features as complex as the dog's own vantage point, it's not at all clear why we should think that a dog would have trouble perceptually

33 For an overview of the range of different views of perceptual content, see Siegel (2011).

34 However, if one intends the direct causal content view to provide a non-circular account of phenomenological directness, a perceptual content can't have as a constituent a certain sort of mode of presentation picking out the direct causal dependence relation. According to Chalmers (2004) and Thompson (2009) the modes of presentation of properties included in perceptual contents have a form like: the property that normally causes experiences with a certain specific phenomenology in the subject. If the direct causal dependence relation were picked out by a mode of presentation like the causal relation that experiences possessing phenomenological directness in the subject normally stand in to the objects of such experiences, then an explanation of phenomenological directness that appealed to such contents would be circular. 
representing that an experience is caused by (or that it directly causally depends on) some object.

Another way to characterize the complaint would be to say we know from first-person reflection that the phenomenology of perceptual experience is simple - such phenomenology is just not as complex as it would have to be if perceptual experiences represented their own direct causal dependence on physical things. ${ }^{35}$ However, it's simply false that in order for an experience to represent some complex feature that the corresponding phenomenology of that experience must be similarly complex. Space and time are complex; but while perceptual experiences represent spatial and temporal relations, there is nothing particularly complex about the characteristic phenomenology of the representation of spatial and temporal relations (for instance, we have no trouble imagining cognitively unsophisticated creatures like dogs having experiences with such phenomenology). Similar points apply to perceptually representing that an experience directly causally depends on some object. Experience and direct causal dependence are complex; but in order for an experience to represent that it directly causally depends on some object, the phenomenology of that experience does not need to be particularly complex. According to the direct causal content view, the phenomenological directness of a perceptual experience just is the characteristic phenomenology of the representation of the relation of direct causal dependence between the experience and the object of the experience. Consequently, there is no reason to believe that the direct causal content view demands too much of perceptual phenomenology.

\section{Conclusion}

As we have seen, many philosophers claim that naïve realism provides a better account of the distinctive phenomenology of perceptual experiences than the content view does, and that therefore we have a compelling reason to prefer naïve realism to the content view. However, because the naïve realist explains phenomenological directness by appealing to a feature of veridical experiences that hallucinations lack, the view has a particular difficulty handling the phenomenological directness of hallucinations. Specifically, the naïve realist has to either deny that hallucinations possess this phenomenology, or grant that they possess this phenomenology and either refuse to provide an explanation or provide one distinct from his explanation of the

For instance, Chalmers $(2006,63)$ considers an objection of this sort to his view that "the normal cause of such-and-such an experience" is included in the contents of perceptual experiences. 
phenomenological directness of veridical experiences. The naïve realist has a preferable account of the phenomenology at issue, then, only so long as no variety of the content view can provide a satisfactory and unified account of the phenomenological directness of both veridical and hallucinatory perceptual experiences.

For the reasons outlined above, I maintain that a particular version of the content view - the direct causal content view — provides just such an account. According to this view, to have a perceptual experience is to stand in the perceptually-experiencing-relation to a specific sort of content, and standing in the perceptually-experiencing-relation to this sort of content suffices for phenomenological directness. And since according to this view hallucinations are the same type of propositional attitude and also possess the relevant sort of content, the direct causal content view provides a unified explanation of the phenomenological directness of both veridical and hallucinatory experiences. Consequently, since the present view provides a better account of the phenomenological facts at issue - since it provides a more satisfying solution to the phenomenological problem - we have a compelling reason to prefer the direct causal content view to naïve realism.

\section{References}

Aggernaes, A. 1972. "The Experienced Reality of Hallucinations and Other Psychological Phenomena." Acta Psychiatrica Scandinavica 48: 220-38.

Aleman, André and Frank Larøi. 2008. Hallucinations: The Science of Idiosyncratic Perception. Washington, DC: American Psychological Association.

Alston, William. 1999. "Back to the Theory of Appearing." In Philosophical Perspectives 13: Epistemology, edited by James Tomberlin, 181-203. Malden, MA: Blackwell.

Armstrong, D. M. 1991. "Intentionality, Perception, and Causality: Reflections on John Searle's Intentionality." In John Searle and his Critics, edited by Ernest Lepore and Robert Van Gulick, 149-58. Cambridge, MA: Blackwell.

Block, Ned. 1995. "On a Confusion about a Function of Consciousness." Behavioral and Brain Sciences 18: 227-47.

_. 1996. "Mental Paint and Mental Latex." In Philosophical Issues 7: Perception, edited by Enrique Villanueva, 19-49. Atascadero, CA: Ridgeview.

Brewer, Bill. 2004. "Realism and the Nature of Perceptual Experience." In Philosophical Issues 14: Epistemology, edited by Ernest Sosa and Enrique Villanueva, 61-77. Malden, MA: Blackwell. 
- 2011. Perception and Its Objects. Oxford: Oxford University Press.

Byrne, Alex. 2009. "Experience and Content." Philosophical Quarterly 59: 429-51.

— tion, Action, Knowledge, edited by Adrian Haddock and Fiona Macpherson, 57-94. Oxford: Oxford University Press.

Campbell, John. 2002. Reference and Consciousness. Oxford: Clarendon Press.

Chalmers, David. 2004. "The Representational Character of Experience." In The Future for Philosophy, edited by Brian Leiter, 153-81. Oxford: Clarendon Press.

—. 2006. "Perception and the Fall from Eden." In Perceptual Experience, edited by Tamar Szabó Gendler and John Hawthorne, 49-125. Oxford: Clarendon Press.

Crane, Tim. 2006. “Is There a Perceptual Relation?" In Perceptual Experience, edited by Tamar Szabó Gendler and John Hawthorne, 126-46. Oxford: Clarendon Press.

—. 2011. "The Problem of Perception." In The Stanford Encyclopedia of Philosophy, edited by Edward Zalta. http://plato.stanford.edu/archives/spr2011/entries/perception-problem/.

Farkas, Katalin. Forthcoming. "A Sense of Reality." In Hallucination, edited by Fiona Macpherson and Dimitris Platchais.

ffytche, D. H., R. J. Howard, M. J. Brammer, A. David, P. Woodruff, and S. Williams. 1998. "The Anatomy of Conscious Vision: An fMRI Study of Visual Hallucinations." Nature Neuroscience 1: $738-42$.

Fish, William. 2009. Perception, Hallucination, and Illusion. Oxford: Oxford University Press.

Harman, Gilbert. 1990. "The Intrinsic Quality of Experience." In Philosophical Perspectives, 4: Action Theory and Philosophy of Mind, edited by James Tomberlin, 31-52. Atascadero, CA: Ridgeview.

Hellie, Benj. 2007. "Factive Phenomenal Characters." In Philosophical Perspectives 21: Philosophy of Mind, edited by John Hawthorne, 259-306. Malden, MA: Blackwell.

—. Forthcoming. "The Multidisjunctive Conception of Hallucination." In Hallucination, edited by Fiona Macpherson and Dimitris Platchais.

Husserl, Edmund. 1900/1970. Logical Investigations. Translated by J. N. Findlay. London: Routledge \& Kegan Paul.

Johnston, Mark. 2004. "The Obscure Object of Hallucination." Philosophical Studies 120: 113-83. 
Kennedy, Matthew. 2009. "Heirs of Nothing: The Implications of Transparency." Philosophy and Phenomenological Research 79: 574604.

Langsam, Harold. 1997. "The Theory of Appearing Defended." Philosophical Studies 87: 33-59.

Martin, M. G. F. 1997. "The Reality of Appearances." In Thought and Ontology, edited by Mark Sainsbury, 81-106. Milano: Franco Angeli.

2004. "The Limits of Self-Awareness." Philosophical Studies 120: $37-89$.

2006. "On Being Alienated." In Perceptual Experience, edited by Tamar Szabó Gendler and John Hawthorne, 354-410. Oxford: Clarendon Press.

Nudds, Matthew. 2009. "Recent Work in Perception: Naïve Realism and its Opponents." Analysis 69: 334-46.

Oertel, Viola, Anna Rotarska-Jagiela, Vincent G van de Ven, Corinna Haenschel, Konrad Maurer, and David E. J. Linden. 2007. "Visual Hallucinations in Schizophrenia Investigated with Functional Magnetic Resonance Imaging." Psychiatry Research: Neuroimaging 156: 269-73.

Ohayon, Maurice. 2000. "Prevalence of Hallucinations and their Pathological Associations in the General Population." Psychiatry Research 91: 153-64.

Pautz, Adam. 2007. "Intentionalism and Perceptual Presence." In Philosophical Perspectives 21: Philosophy of Mind, edited by John Hawthorne, 495-541. Malden, MA: Blackwell.

—. 2009. "What are the Contents of Experiences?" Philosophical Quarterly 59: 483-507.

—. 2010. "Why Explain Visual Experience in Terms of Content?" In Perceiving the World, edited by Bence Nanay, 254-309. Oxford: Oxford University Press.

Schellenberg, Susanna. 2011. "Ontological Minimalism about Phenomenology." Philosophy and Phenomenological Research 83: 1-40.

Searle, John. 1983. Intentionality. Cambridge: Cambridge University Press.

. 1991. "Response: Perception and the Satisfactions of Intentionality." In John Searle and his Critics, edited by Ernest Lepore and Robert Van Gulick, 181-92. Cambridge, MA: Blackwell.

Siegel, Susanna. 2006. "Subject and Object in the Contents of Visual Experience." Philosophical Review 115: 355-88.

—. 2010. The Contents of Visual Experience. Oxford: Oxford University Press. 
—. 2011. "The Contents of Perception." In The Stanford Encyclopedia of Philosophy, edited by Edward Zalta. http://plato.stanford .edu/archives/spr2011/entries/perception-contents/.

Siewert, Charles. 1998. The Significance of Consciousness. Princeton: Princeton University Press.

Slade, Peter and Richard Bentall. 1988. Sensory Deception: A Scientific Analysis of Hallucination. Baltimore: The Johns Hopkins University Press.

Smith, A. D. 2002. The Problem of Perception. Cambridge, MA: Harvard University Press.

Speaks, Jeff. 2009. "Transparency, Intentionalism, and the Nature of Perceptual Content." Philosophy and Phenomenological Research 79: 539-73.

Strawson, P. F. 1979. "Perception and Its Objects." In Perception and Identity, edited by G. F. MacDonald, 41-60. Ithaca, NY: Cornell University Press.

Sturgeon, Scott. 2000. Matters of Mind. London: Routledge.

Thau, Michael. 2002. Consciousness and Cognition. Oxford: Oxford University Press.

Thompson, Brad. 2009. "Senses for Senses." Australasian Journal of Philosophy 87: 99-117.

Tien, A. Y. 1991. "Distribution of Hallucinations in the Population." Social Psychiatry and Psychiatric Epidemiology 26: 287-92.

Vega-Encabo, Jesús. 2010. "Hallucinations for Disjunctivists." Phenomenology and the Cognitive Sciences 9: 281-93.

Woodruff, P. W. R. 2004. "Auditory Hallucinations: Insights and Questions from Neuroimaging." Cognitive Neuropsychiatry 9: 73-91. 